\title{
Value of profiling liver function in the elderly
}

\author{
J. R. LUBIN \\ M.B., B.S. \\ B.A. MILLWARD \\ M.B., B.Chir
}

\author{
J. A. Coles \\ M.R.C.P. \\ J. R. CROKER \\ M.R.C.P.
}

Geriatric Department, Middlesex Hospital, Mortimer Street, London WIN $8 A A$

\section{Summary}

The value of measuring three routine tests of liver function was assessed prospectively in $\mathbf{5 2 3}$ geriatric patients. Abnormalities were found in $27 \%$ of patients and were clinically helpful in half of these cases. Profiling liver function, without clinical indication, revealed abnormal results in $17 \%$ of patients and was important in one-third of these (6\% of total). The two most important diagnoses were unsuspected osteomalacia and gall stone disease.

\section{KEY WORDS: alkaline phosphatase, gall stone, osteomalacia.}

\section{Introduction}

In the elderly, disease presentation is commonly non-specific, and patterns of illness are often atypical. Thus, considerable reliance is placed on the use of routine profiling tests in this age group. The value of screening thyroid function is now well established in geriatric practice (Bahemuka and Hodkinson, 1975). We have assessed the contribution made by measuring three routine tests of liver function (serum concentrations of alkaline phosphatase, bilirubin and aspartate aminotransferase) in patients admitted acutely to the Middlesex Hospital Geriatric Department.

\section{Methods}

The value of measuring serum concentrations of alkaline phosphatase (AP), bilirubin and aspartate aminotransferase (AST) was assessed prospectively in 523 consecutive patients admitted during one year, a total of 616 admissions. (August 1980-August 1981). The mean age was 82 years. Two questions were asked:
(1) Were there clinical indications for measuring the

(2) Was knowledge of abnormal function helpful in the management of the patient?

The normal ranges: bilirubin up to $15 \mu \mathrm{mol} / 1$; AST up to $45 \mathrm{iu} / \mathrm{l}$; alkaline phosphatase $20-85 \mathrm{iu} / 1$; $100-280 \mathrm{iu} / 1$.

We took levels of 18 and above for bilirubin, 50 and above for AST. Alkaline phosphatase units changed during the course of the assessment period. We took levels above 90 and above 295 .

The Middlesex Hospital has an acute admissions policy for geriatric patients; the following tests were performed routinely on admission-blood count, urea and electrolytes, liver function, serum calcium and phosphate, chest $\mathrm{X}$-ray and thyroid function. Further investigations were carried out where clinically appropriate. In patients with isolated elevation of serum AP concentration, measurement of serum $\gamma$ glutamyl-transpeptidase activity was used to indicate an hepatic source (Whitfield et al., 1972). Follow-up was available for one year.

\section{Results}

Mixed abnormalities of liver function. Abnormalities of more than one test were found in $\mathbf{4 0}$ patients $(7.6 \%)$ and, in the majority of cases, all three tests were abnormal. The serum AP concentration was raised in 32 patients. The diagnoses are shown in Table 1. The pattern of abnormality indicated a cholestatic cause in five cases (choledochal stones

\begin{tabular}{lr}
$\begin{array}{l}\text { TABLE 1. Causes of mixed abnormalities } \\
\text { of liver function in } 40 \text { patients }\end{array}$ \\
\hline Congestive cardiac failure & 13 \\
Alcohol liver disease & 8 \\
Gall stone disease & 6 \\
Cholecystitis & $(1)$ \\
Choledochal stones & $(5)$ \\
Pneumonia & 3 \\
Drug hepatitis & 2 \\
Viral hepatitis & 1 \\
Carcinoma bile duct & 1 \\
No diagnosis & 7 \\
\hline
\end{tabular}


two, phenothiazines two, bile duct carcinoma one) and hepatocellular damage in four (heart failure one, alcohol two, viral hepatitis one). In the remaining 31 patients the pattern of change was indeterminate.

Isolated elevation of serum bilirubin concentration. This was found in $12.5 \%$ of patients, but was unhelpful in patient management, whether indicated or detected by profiling. The commonest cause of this abnormality was congestive cardiac failure.

TABLE 2. Causes of isolated raised alkaline phosphatase concentration in 101 patients

\begin{tabular}{lr}
\hline Bone disease $(n=51)$ & 23 \\
Osteomalacia & 13 \\
Fractures & 9 \\
Paget's disease & 3 \\
Metastases & 2 \\
Uraemia & 1 \\
Osteomyelitis & \\
& \\
Liver disease $(n=23)$ & 6 \\
Congestion & 6 \\
Gall stone disease & $(2)$ \\
$\quad$ Empyema & $(4)$ \\
$\quad$ Choledochal stones & 3 \\
Alcohol & 3 \\
Metastases & 3 \\
Polymyalgia rheumatica & 1 \\
Chronic disease & 1 \\
Subphrenic abscess & \\
Not diagnosed $(n=27)$ & \\
\hline
\end{tabular}

Isolated elevation of serum alkaline phosphatase concentration. This was found in 101 patients (19.3\%). The underlying diagnoses are shown in Table 2 . In most patients, the serum AP concentration was raised up to two-fold normal levels. Higher values were recorded in patients with liver disease. Gall stones were again common, but unexpected. Osteomalacia was present in 23 patients and was associated with previous gastrectomy (4), malnutrition (3), anticonvulsant therapy (2) and steatorrhoea (2). Four patients with proven osteomalacia were already receiving vitamin $\mathrm{D}$ treatment. The remaining patients were not clinically malnourished, although formal dietary and anthropometric assessments were not made. Diagnosis of osteomalacia was made on biochemical grounds alone. A low 'corrected' serum calcium concentration was present in 14 of the 23 patients and a low serum 25-hydroxy-cholecalciferol level was recorded in 13 patients. None of these patients was suffering from chronic renal failure. Biochemical improvement following vitamin $D$ treat- ment is more important for diagnosis and was noteck in all 19 patients in whom follow-up was available including seven of the nine patients with normalserum calcium concentration. Diagnosis of othet skeletal disease was made by $\mathrm{X}$-ray and isotope bone+ scanning.

Isolated elevation of serum aspartate aminotrans $\frac{\bar{c}}{\mathrm{~s}}$ ferase concentration was not considered. In foug patients with mixed abnormalities of liver function? this enzyme was significantly raised suggesting hepatocellular damage (see above).

TABLE 3. Value of performing liver function tests in 523 geriatro patients (Figures in parenthesis denote numbers "clinically helpful

\begin{tabular}{|c|c|c|}
\hline & Indicated & Profiling \\
\hline Mixed abnormalities & $15(12)$ & $25(2)$ \\
\hline Isolated raised alkaline phosphatase & $39(25)$ & $62(25)$ \\
\hline
\end{tabular}

TABLE 4. Diagnoses of abnormal profiling tests (clinically helpful) i 523 geriatric patients

\begin{tabular}{|c|c|c|}
\hline & $\begin{array}{c}\text { Isolated } \\
\text { mixed alkaline } \\
\text { phosphatase }\end{array}$ & Mixed \\
\hline Osteomalacia & 12 & - \\
\hline Gall stone disease & 6 & 2 \\
\hline Polymyalgia rheumatica & 3 & - \\
\hline Alcohol liver disease & 2 & 3 \\
\hline Lives metastases & 2 & - \\
\hline Drug hepatitis & - & 1 \\
\hline Viral hepatitis & - & 1 \\
\hline Total & 25 & 7 \\
\hline
\end{tabular}

The value of performing liver function tests is shown in Tables 3 and 4 . In patients with mixed abnormalities of liver function, the tests were indicated in 15 patients (eight of whom were jaundiced and performed as a profile in 25 cases. In patients with isolated elevation of serum AP concentration? the tests were indicated in 39 patients and performed for profiling in 62 cases. Overall patient management. was aided in 32 of the 87 patients in whom abnormalities of liver function were detected by profiling alone (Table 4).

Gall stone disease was present in 12 patient (cholecystitis one, empyema of gall bladder two choledochal stones nine) and was detected by profilo ing tests in eight cases. In six of these patients elevation of serum AP concentration was the only? abnormality of liver function detected. Gall bladdero 
disease was diagnosed by ultrasound (three) and confirmed by surgery (one). Choledochal stones were suggested by ultrasound in three cases (dilated biliary tree), but confirmed by endoscopic-retrogradecholangio-pancreatography (ERCP) in five cases and by post-mortem in four cases, two of whom were unsuspected. Duodenoscopic sphincterotomy was successful in removing choledochal stones in five patients (Mee et al., 1981).

\section{Discussion}

In the elderly, elevations of serum concentration of alkaline phosphatase, bilirubin and aspartate aminotransferase are due to disease and not to ageing itself (Hodkinson and MacPherson, 1973; Kampmann, Sinding and Jorgensen, 1975). Hodkinson and MacPherson (1973) have stressed the difficulty of correlating biochemical abnormality with pathology, particularly when several diseases may be present. In our series, the cause for such elevation was found in $73 \%$ of cases. In the remainder, the exact reason for the abnormalities was uncertain or unknown; in many cases, it was clinically inappropriate to investigate the results further.

The distinction between an 'indicated' and a 'profiling' test is often fine and depends not only on clinical judgement, but also on attitudes to investigation. A test was indicated when there was expectation of finding raised levels due to pathology. Abnormalities of liver function, both mixed and isolated, were found in 141 of 523 patients $(27 \%)$ and were clinically helpful in half these cases. This figure is probably an underestimate of the true value of measuring liver function since only raised abnormalities have been considered. The finding of normal function may also contribute to patient management. Sewell et al., (1981) found there was no value in measuring liver function tests in the elderly. However, in the present series, profiling liver function, without clinical indication, produced abnormal results in $16.6 \%$ of all patients examined. In just over one-third of these $(6 \%$ of total), the results were clinically helpful.

Measurement of serum AP concentration proved particularly rewarding. Raised levels were recorded in $\mathbf{3 2}$ of $\mathbf{4 0}$ patients with 'mixed' abnormalities and as an isolated finding in 101 patients. Nearly all patients with a raised serum AP level will have a hepatobiliary or a skeletal cause for such elevation. Isoenzyme analysis of serum AP concentration is difficult and most laboratories use estimation of other hepatic enzymes (5-nucleotidase or $\gamma$-glutamyl transpeptidase) to indicate its source. In this series, the two most important diagnoses were unexpected osteomalacia and gall stone disease. Fractures, Paget's disease, bony secondaries, hepatic metastases and alcoholic liver disease were also documented and are well-recognized causes for elevation of serum AP concentration. This abnormality was recorded in three patients with polymyalgia rheumatica. The enzyme originates from the liver and is a useful marker of this condition; it parallels both disease activity and the erythrocyte sedimentation rate, returning to normal with steroid treatment (Glick, 1972).

We detected biochemical osteomalacia in $4.4 \%$ of our patients. Similar results have been recorded in geriatric populations by other histological (Anderson et al., 1966) and biochemical methods (Hodkinson and MacPherson, 1973). The significance of such sub-clinical osteomalacia is uncertain, although a high rate has been found in elderly patients with fracture neck of femur (Jenkins et al., 1973). There is a poor correlation between biochemistry and histology (Anderson et al., 1966; Jenkins et al., 1973). Low levels of serum vitamin $\mathrm{D}$ are found in osteomalacia, but the significance of this finding in the elderly remains uncertain (Baker et al., 1979; Corless et al., 1975). Plasma AP activity remains the best single routine biochemical screening test for osteomalacia, although a high false positive rate may occur (Peach et al., 1982; Hodkinson and MacPherson, 1973). Although histological assessment is more definitive, bone biopsy may be painful and quantification of osteoid may be difficult. It is our practice to treat patients with biochemical osteomalacia with vitamin D without performing bone biopsies and to observe their biochemical response. Although our methods will not have detected all patients with osteomalacia, it is clearly foolish to ignore the clue of a raised serum AP level, even when the serum calcium is normal.

Biliary stones are an important and treatable cause of illness in the elderly. Although most gall stones are 'silent', they may present suddenly with cholangitis and septicaemia. Stones in the common bile duct are particularly dangerous. In this series, gall stone disease was suspected clinically in four patients and indicated by profiling tests in eight cases. A raised serum AP level may be the only marker of gall stone disease (Jones et al., 1982). In a large series of elderly patients with choledochal stones, $10 \%$ presented with elevation of this enzyme without jaundice (Mee et al., 1981). All patients with an hepatic cause for a raised AP level should undergo an ultrasound examination of the hepato-biliary region. Unfortunately, choledochal stones may cause isolated elevation of the serum AP level without dilatation of the biliary tree. Where clinically appropriate intravenous cholangiography or endoscopic-retrograde-cholangiography may be needed to exclude their presence. Duodenoscopic sphincterotomy is a great advance in the management of choledochal stones and is particularly appropriate in elderly subjects (Mee et al., 1981). 


\section{Conclusion}

Measurement of liver function in the elderly is rewarding. Abnormal results were detected in $27 \%$ of patients, but were only clinically indicated in $38 \%$ of these cases. Profiling liver function (without clinical indication) was clinically important in $6 \%$ of patients. Osteomalacia and gall stone disease were the two main unsuspected diagnoses.

\section{Acknowledgment}

We thank Dr A. L. Miller of the Courtauld Institute of Biochemistry for his help and advice.

\section{References}

Anderson, I., Campbell, A.E.R., DunN, A. \& Runciman, J.B.M. (1966) Osteomalacia in elderly women. Scottish Medical Journal, 11, 429.

BAHEMUKA, M. \& HodKINSON, H.M. (1975) Screening for hypothyroidism in the elderly patient. British Medical Journal, 2, 601 .

Baker, M.R., MCDonnell, H., PeACock, M. \& Nordin, B.E.C. (1979) Plasma 25-hydroxy vitamin D concentration in patients with fractures of the femoral neck. British Medical Journal, 1, 589.
Corless, D., BeER, M., Boucher, B.J., GuPtA, S.P. \& COHENR.D. (1975) Vitamin D status in long-stay geriatric patients Lancet, i, 1404.

GLICK, E.N. (1972) Raised serum alkaline phosphatase levels in. polymyalgia rheumatica. Lancet, ii, 328.

HODKINSON, H.M. \& MACPHERSON, C.K. (1973) Alkaline phospha@ tase in a geriatric in-patient population. Age and Ageing, 2, 28.

JenKINS, D.H.R., RoberTS, J.G., WebSTER, D. \& WiLliams, E. (1973) Osteomalacia in elderly patients with fracture of th femoral neck. Journal of Bone and Joint Surgery, 55, 575.

JONES, S.N., ASKEW, C.M., BEYNON, G.P.J. \& CROKER, J.R. (1982§ Isolated elevation of serum alkaline phosphatase and biliary disease in the elderly. Postgraduate Medical Journal, 58, 85.

KAMPMANN, J.P., Sinding, J. \& JoRgenSEN, I.M. (1975) Effect of age on liver function. Geriatrics, 30, 91 .

MeE, A.S., VAllon, A.G., CROKER, J.R. \& CotTon, P.B. (1981)े Non-operative removal of bile duct stones by duodenoscopie sphincterotomy in the elderly. British Medical Journal, 283, 52 10

PeACH, H., Compston, J.E., Vedi, S. \& HoRTon, L.W.L. (1982 Value of plasma calcium, phosphate, and alkaline phosphatase measurements in the diagnosis of histological osteomalaciar Journal of Clinical Pathology, 35, 625.

SEWELL, J.M.A., SPOONER, L.L.R., DiXon, A.K. \& RubENSTEIN, D. (1981) Screening investigations in the elderly. Age and Ageing, 10, 165.

Whitfield, J.B., POUNDER, R.E., NEAle, G. \& Moss, D.W. (1972\% Serum $\gamma$-glutamyl transpeptidase activity in liver disease. Gut, 13 702.

(Accepted 4 May 1983) 